\title{
Hepatic lipase deficiency produces glucose intolerance, inflammation and hepatic steatosis
}

\author{
Irene Andrés-Blasco ${ }^{1, *}$, Andrea Herrero-Cervera ${ }^{1{ }^{1 *}}$, Ángela Vinué1, \\ Sergio Martínez-Hervás ${ }^{1,2,3}$, Laura Piqueras', María Jesús Sanz ${ }^{1,4}$, \\ Deborah Jane Burks ${ }^{3,5}$ and Herminia González-Navarro ${ }^{1,3}$ \\ ${ }^{1}$ Institute of Health Research-INCLIVA, Avenida Menéndez Pelayo, 4, 46010 Valencia, Spain \\ ${ }^{2}$ Endocrinology and Nutrition Department Clinic Hospital and Department of Medicine, University of Valencia, \\ Valencia, Spain \\ ${ }^{3}$ CIBER de Diabetes y Enfermedades Metabólicas asociadas (CIBERDEM), Valencia, Spain \\ ${ }^{4}$ Department of Farmacology, University of Valencia, Valencia, Spain \\ ${ }^{5}$ Centro de Investigación Príncipe Felipe, Valencia, Spain \\ *(I Andrés-Blasco and A Herrero-Cervera contributed equally to this work)
}

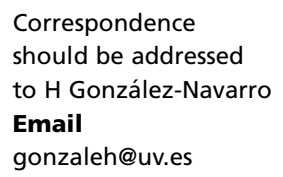

\begin{abstract}
Metabolic syndrome and type 2 diabetes mellitus constitute a major problem to global health, and their incidence is increasing at an alarming rate. Non-alcoholic fatty liver disease, which affects up to $90 \%$ of obese people and nearly $70 \%$ of the overweight, is commonly associated with MetS characteristics such as obesity, insulin resistance, hypertension and dyslipidemia. In the present study, we demonstrate that hepatic lipase (HL)-inactivation in mice fed with a high-fat, high-cholesterol diet produced dyslipidemia including hypercholesterolemia, hypertriglyceridemia and increased non-esterified fatty acid levels. These changes were accompanied by glucose intolerance, pancreatic and hepatic inflammation and steatosis. In addition, compared with $W T$ mice, $\mathrm{HL}^{-1-}$ mice exhibited enhanced circulating MCP1 levels, monocytosis and higher percentage of CD4+Th17+ cells. Consistent with increased inflammation, livers from $\mathrm{HL}^{-1-}$ mice had augmented activation of the stress SAPK/JNK- and p38-pathways compared with the activation levels of the kinases in livers from $W T$ mice. Analysis of $\mathrm{HL}^{-1-}$ and $W T$ mice fed regular chow diet showed dyslipidemia and glucose intolerance in $\mathrm{HL}^{-1-}$ mice without any other changes in inflammation or hepatic steatosis. Altogether, these results indicate that dyslipidemia induced by $\mathrm{HL}$-deficiency in combination with a high-fat, high-cholesterol diet promotes hepatic steatosis and inflammation in mice which are, at least in part, mediated by the activation of the stress SAPK/JNK- and p38-pathways. Future studies are warranted to asses the viability of therapeutic strategies based on the modulation of these kinases to reduce hepatic steatosis associated to lipase dysfunction.
\end{abstract}

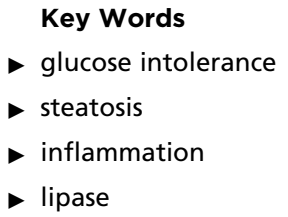

Journal of Endocrinology (2015) 227, 179-191

\section{Introduction}

Patients with Metabolic syndrome (MetS) and type 2 diabetes mellitus (T2DM) have a shorter lifespan compared with the general population (Zambon et al.
2009). They constitute a major problem to global health, and their incidence is increasing at an alarming rate due to population aging and to sedentary lifestyle patterns 
(Wild et al. 2004). Metabolic alterations that define MetS include insulin resistance (IR), abdominal obesity, glucose intolerance, hypertension and dyslipidemia.

Hypertriglyceridemia and high levels of non-esterified fatty acids (NEFA) in the MetS promote abnormal accumulation of lipids within the liver, in a form of steatosis or non-alcoholic fatty liver disease (NAFLD) (Bugianesi et al. 2005). Thus, NAFLD affects up to $90 \%$ of obese people and nearly $70 \%$ of the overweight subjects, and it is thought to be the hepatic event in the MetS. In addition, NAFLD is commonly associated with MetS risk factors such as obesity, IR, hypertension and dyslipidemia. Albeit the precise mechanisms linking characteristics of the MetS and NAFLD are not completely known, a complex relationship exists between the two (Marchesini \& Marzocchi 2007, Mitsutake et al. 2011). In this sense, an excess of glucose and triglycerides, which are key components in the MetS, is produced by fatty liver (Anstee et al. 2013, Yki-Jarvinen 2014). On the other hand, IR development, which alters carbohydrate and lipid metabolism, increases triglyceride accumulation in the liver (Samuel et al. 2010, Samuel \& Shulman 2012). Moreover, excess fat in adipocytes, which occurs in overweight and obesity, aggravates fatty liver disease by increasing the release of pro-inflammatory mediators such as MCP1, IL-6 and TNF $\alpha$ (Sahini \& Borlak 2014). Of note, one of the main contributions to steatosis in NAFLD is an excess of circulating free fatty acids (FFA) and triglycerides which are also characteristics of the MetS and IR.

Hepatic lipase (HL) is a key enzyme in lipid metabolism and biology that hydrolyses triglycerides and phospholipids in lipoproteins, thus facilitating their clearance and metabolism (Santamarina-Fojo et al. 2004, Teslovich et al. 2010). HL deficiency in the mice produces mild dyslipidemia including increased total cholesterol, phospholipids and HDL-cholesterol (Homanics et al. 1995). Upon acute fat loading (Homanics et al. 1995) or in combination with other genetic deficiencies such as apolipoprotein E deficiency or LDL-receptor deficiency (Mezdour et al. 1997, Freeman et al. 2007), HL inactivation in the mice also produces hypertriglyceridemia and atheroma lesions. Interestingly, HL deficiency did not change body weight or food intake in the mice (Escola-Gil et al. 2013). In humans, genetic studies have linked HL gene polymorphisms to progression of abdominal obesity and T2DM (Todorova et al. 2004). Reduced abdominal obesity and weight loss in subjects are associated with reduced HL activity and prevention of T2DM (Bergeron et al. 2001, Todorova et al. 2004). Other studies have shown that HL gene is associated with dyslipidemia characterised by high levels of atherogenic LDL, low HDL and high triglycerides (Teslovich et al. 2010). The role of HL in cardiovascular disease progression in humans is controversial and HL increased levels are beneficial in patients with hypercholesterolemia (Dugi et al. 2001) but detrimental in subjects with central obesity and IR (Teran-Garcia et al. 2005, Zhang et al. 2006, Brunzell et al. 2011). Therefore, the effect of HL in disease progression is highly dependent on the underlying lipoprotein and lipid phenotype (Brunzell et al. 2011).

Despite the preceding association studies, the effect of HL inactivation in the glucose metabolism homeostasis and in the development of fatty liver disease has not been fully investigated. To this end, HL-deficient $\left(\mathrm{HL}^{-/-}\right)$and WT mice were fed a high-fat, high-cholesterol (HFHC) diet for four months or fed regular chow diet (RCD) and glucose metabolism, hepatic steatosis, pancreatic characteristics and the associated inflammation were analysed.

\section{Materials and methods}

\section{Mice and diets}

Animal care was in accordance with institutional guidelines and the 2010/63/EU directive from the European Parliament. $H L^{-/-}$(Jackson laboratories) and $W T$ (Charles River) mice were on C57BL/6J background. After weaning, mice were maintained on a RCD $(2.8 \%$ fat; Panlab, Barcelona, Spain) and at two months of age, mice were placed on a HFHC diet $(10.8 \%$ fat, $0.75 \%$ cholesterol, S4892-E010, Ssniff, Germany) for 16 weeks or left on RCD for 16 more weeks.

\section{Metabolic measurements}

Plasma triglycerides, total cholesterol (WAKO, Neuss, Germany) and non-esterified fatty acids (NEFA, SIGMA) levels were measured using enzymatic procedures in overnight-fasted mice. HDL-cholesterol (HDL-C) was determined after precipitation of the apolipoprotein B-containing lipoproteins with dextran sulphate/ $\mathrm{MgCl} 2$ (SIGMA) (Gonzalez-Navarro et al. 2010). For the glucose tolerance test (GTT), overnight-fasted mice received an intraperitoneal injection of glucose $(2 \mathrm{~g} / \mathrm{Kg}$ of body weight, BW, SIGMA) and plasma glucose and insulin levels were analysed at different time-points using a glucometer (Ascensia Elite, BAYER, Leverkusen, Germany) and an ultrasensitive anti-mouse insulin ELISA (MERCODIA, Uppsala, Sweden) respectively (Gonzalez-Navarro et al. 2007, 2008). Plasma glucose and insulin levels in feed

Published by Bioscientifica Ltd. 
state were measured between $10: 00$ and $12: 00 \mathrm{~h}$ in the morning. For the insulin tolerance test (ITT), $4 \mathrm{~h}$-fasted mice received an intraperitoneal injection of insulin (0.5 U/Kg of BW ACTRAPID, NovoNordisk, Bagsvaerd, Denmark) and plasma glucose levels were measured as before (Gonzalez-Navarro et al. 2013). HOMA-IR index was determined using the formula: fasting plasma glucose $(\mathrm{mmol} / \mathrm{l}) \times$ fasting plasma insulin $(\mu \mathrm{U} / \mathrm{l}) / 22.5$. Liver triglyceride content was determined by tissue digestion and saponification in ethanolic potassium hydroxide followed by enzymatic measurement of glycerol content (Free Glycerol Reagent, SIGMA) (Norris et al. 2003).

\section{Pancreatic islet isolation and insulin secretion assay}

For islet isolation, mice were infused with Krebs buffer $\left(127 \mathrm{mM} \mathrm{NaCl}, 5 \mathrm{mM} \mathrm{KCl}, 3 \mathrm{mM} \mathrm{CaCl} 2,1.5 \mathrm{mM} \mathrm{MgCl}_{2}\right.$, $24 \mathrm{mM} \mathrm{NaHCO}, 6 \mathrm{mM}$ Hepes, $2 \mathrm{mg} / \mathrm{ml}$ glucose, $0.1 \%$ albumin, equilibrated with $5 \% \mathrm{CO}_{2}$ in $\mathrm{O}_{2}$ ) and their pancreases were dissected and digested with collagenaseNB8 $\left(1 \mathrm{mg} / \mathrm{ml}\right.$, Serva, Heidelberg, Germany) at $37^{\circ} \mathrm{C}$ in a shaking waterbath for $20 \mathrm{~min}$. Islets were handpicked under stereoscope (Vinue et al. 2015). Insulin secretion was evaluated by a glucose-stimulated insulin secretion assay at low $(2.8 \mathrm{mmol} / \mathrm{l})$ and high $(16.7 \mathrm{mmol} / \mathrm{l})$ glucose concentrations in KRBH buffer $(140 \mathrm{mM} \mathrm{NaCl}, 2.5 \mathrm{mM}$ $\mathrm{KCl}, 2.5 \mathrm{mM} \mathrm{CaCl}_{2}, 1 \mathrm{mM} \mathrm{MgCl}_{2}, 20 \mathrm{mM}$ Hepes, $2 \mathrm{mg} / \mathrm{ml}$ glucose, $0.1 \%$ albumin). Six assays (five islets each) were performed per condition. Insulin concentrations were measured by ELISA. The stimulation index was calculated as the ratio of glucose-stimulated insulin to basal insulin normalised by the insulin content.

\section{Liver and pancreas immunostainings}

Livers and pancreases were sectioned from mice sacrificed by cervical dislocation after perfusion with PBS and fixed with $4 \%$ paraformaldehyde/PBS $4 \mathrm{~h}$ and paraffinembedded as described (Gonzalez-Navarro et al. 2013). $\beta$-cell mass was measured as the islet area relative to total pancreatic area (\%) obtained from the analysis of 10-12 slides (separated $125 \mu \mathrm{m}$ ) per mouse stained with an anti-insulin antibody (described in the following paragraph). Lipid droplet (LD) images were obtained from hematoxylin/eosin stained sections.

The immunohistochemistry protocol consisted of peroxidase inactivation $\left(\mathrm{H}_{2} \mathrm{O}_{2} 0.3 \%\right.$ in distilled water), antigen retrieval with Sodium Citrate buffer $10 \mathrm{mM}, \mathrm{pH}$ 6.5, blocking (horse serum 5\%, $1 \mathrm{~h}$, RT), incubation with primary antibodies (rabbit polyclonal anti-insulin 1/200 dilution, sc-9168, Santa Cruz Biotechnologies; rat monoclonal anti-F4/80 1/50 dilution, MCA497G, AbD Serotec, ThermoFisher, Kidlington, UK) followed by biotinylated goat anti-rat or anti-rabbit secondary antibodies $(1 \mathrm{~h}, \mathrm{RT}$, 1/500 dilution, sc-2491, sc-2041, Santa Cruz Biotechnologies), streptavidin-HRP (TS-060-HR, ThermoScientific, Cheshire, UK) and DAB substrate (SK4100, Vector Laboratories, Burlingame, CA, USA). Slides counterstained with hematoxylin were mounted with EUKITT (A10500, Deltalab, Barcelona, Spain). Images were captured with an OPTIKAM-PRO5 digital camera mounted on a stereomicroscope (OPTIKA, Barcelona, Spain) and analysed by computer-assisted morphometry (SigmaScan, Pro5).

Double immunofluorescences insulin/glucagon, insulin/CD3 + and insulin/Ki67 consisted of antigen retrieval (Sodium Citrate buffer $10 \mathrm{mM}$, pH 6.5 for insulin/glucagon and insulin/Ki67 and with Tris EDTA buffer $10 \mathrm{mM} \mathrm{pH}$ 9, for insulin/CD3 + high pressure and temperature) and blocking (horse serum 5\%, $1 \mathrm{~h}, \mathrm{RT}$ ), incubation (overnight at $4{ }^{\circ} \mathrm{C}$ ) with primary antibodies (mouse monoclonal antiglucagon, 1/300, G2654, SIGMA and rabbit polyclonal anti-insulin 1/200 dilution, sc-9168, Santa Cruz Biotechnologies; mouse monoclonal anti-insulin 1/300, I2018 SIGMA; rabbit monoclonal anti-Ki67, Clone SP6,MAD-000310QD, VITRO) followed by incubation $(1 \mathrm{~h}$ at RT) with a goat anti-mouse IgG Alexa Fluor 594 and an anti-rabbit IgG AlexaFluor488 (1/200, A11005 and A21206, Invitrogen) secondary antibodies. Nuclear staining was performed with DAPI $(1 / 1000,20 \mathrm{~min}, \mathrm{D} 1306$, Invitrogen) and slides were mounted with Slow-Fade Gold reagent (S36936, Invitrogen) and analysed with an inverted fluorescent microscope (LEICA DMI 3000B).

\section{Enzyme-Linked ImmunoSorbent Assay (ELISA)}

MCP1 and TNF- $\alpha$ circulating levels were determined in isolated plasma from heparinised blood (10 U heparin/ml) from mice using the Quantikine ELISA kits (R\&D Systems, Minneapolis, MN, USA).

\section{Flow cytometry}

Circulating monocytes were determined in $10 \mu \mathrm{l}$ of heparinised whole blood incubated for $30 \mathrm{~min}$ at RT with Ly6C-PerCP (BD Pharmingen, Madrid, Spain) and CD115-APC (Biolegend, San Diego, CA, USA). For lymphocytes, $10 \mu \mathrm{l}$ of heparinised whole blood was incubated for 30 min RT with $5 \mu$ l Brilliant Stain Buffer $(563794$, BD) and with Brilliant violet (BV)-rat anti-mouse CD4 (562891, BD), BV-rat anti-mouse CD8a (563068, BD), PE-hamster

Published by Bioscientifica Ltd. 
anti-mouse CD69 (553237, BD) and APC-hamster antimouse CD3e (553066, BD). Incubation with lysing solution (BD Facs Lysing solution) was done before analysis by flow cytometry (FACSVerse BD Biosciences). To detect functionally-polirised CD4+T lymphocyte, $100 \mu \mathrm{l}$ of heparinised whole blood was stained with the mouse Th17/Treg phenotyping kit (BD Pharmingen, Madrid, Spain) to detect CD4+Foxp3+ and CD4+IL17 cells. Analysis of Ly6C ${ }^{\text {low }}$ - and $\mathrm{Ly}_{6} \mathrm{C}^{\text {hi }}$-subsets were determined in $\mathrm{CD} 115+$ populations.

\section{Western blot analysis}

Liver protein lysates were obtained in the presence of the ice-cold lysis TNG buffer (Tris-HCl $50 \mathrm{mM}, \mathrm{pH} 7.5, \mathrm{NaCl}$ $200 \mathrm{mM}$, Tween-20 1\%, NP-40 0,2\%) supplemented with Complete Mini cocktail, PhosSTOP (Roche, Mannheim, Germany), ß-glicerolphosphate $50 \mathrm{mM}$ (SIGMA), $2 \mathrm{mM}$ phenylmethylsulfonyl Fluoride (PMSF, ROCHE, Mannheim, Germany) and $200 \mu \mathrm{M} \mathrm{Na}_{3} \mathrm{VO}_{4}$ (SIGMA). Protein extracts $(50-100 \mu \mathrm{g})$ were prepared in laemmli's buffer and analysed by $12 \%$ polyacrilamide gel electrophoresis and western blot (Gonzalez-Navarro et al. 2013, MartinezHervas et al. 2014). The primary antibodies used were: rabbit polyclonal anti-Phospho-p38 (1/200, sc-17852-R, Santa Cruz Biotechnologies), rabbit polyclonal anti-p38 (1/200, sc-535, Santa Cruz Biotechnologies), rabbit polyclonal anti-Phospho-SAPK/JNK (1/200, Thr183/Tyr185, 9251 Cell Signaling), rabbit polyclonal SAPK/JNK (1/200, 56G8, 9258 Cell Signaling) and mouse monoclonal anti$\alpha$-tubulin (1/500, sc-8035, Santa Cruz Biotechnologies). The HRP-conjugated secondary antibodies (1/500, Santa Cruz Biotechnologies) used were: anti-mouse IgG-HRP (sc-2005) and goat anti-rabbit IgG-HRP (sc-2004). The immunocomplexes were detected with an ECL Plus detection kit (ThermoFisher Scientific, Barcelona, Spain).

\section{Gene expression analysis by quantitative real-time PCR}

RNA $(0.5-1 \mu \mathrm{g})$ from mouse liver obtained with TRIzol Reagent (Invitrogen), was retrotranscribed with the Maxima First-Strand cDNA Synthesis kit and amplified with Luminars Color-HiGreen/High ROX qPCR MasterMIX (Fermentas, Madrid, Spain) on 7900Fast System. Results were analysed with the provided software (Applied Biosystems). The mRNA levels were normalised to endogenous gene Cyclophilin expression and relativised to $W T$ mRNA levels. The primers were designed with the primer express programme and were (Forward: Fw; Reverse: Rv): cyclophilin Fw: 5'-TGGAGAGCACCAAGACAGACA-3' and Rv: 5'-TGCCGGAGTCGACAATGAT-3'; Tnf- $\alpha$ Fw: 5'-CCCACACCGTCAGCCGATTT-3' and Rv: 5'-GTCTAAGTACTTGGGCAGATTGACC-3'; Mcp1 Fw: 5'-GCCCAGCACCAGCACCAG-3' and Rv: 5'-GGCATCACAGTCCGAGTC-3'; Jnk1 Fw: 5'-CAACGTCTGGTATGATCCTTCAGA-3'; Rv: 5'-GCTCCCTCTCATCTAACTGCTTGT-3'; p38 $\alpha$ Fw: 5'-GACTTTCCCTGTTGGACAGCTT-3'; Rv: 5'-CAACAGACTGACCCGCTAAGG-3'.

\section{Statistical analysis}

Data are presented as the mean \pm s.E.M. Differences were evaluated using a two-tail, unpaired Student's $t$-test and were considered statistically significant when $P \leq 0.05$ (GraphPad Prism Software Inc, La Jolla, CA, USA). Outliers identified with Grubbs' test (GraphPad Prism Software) were not considered.

\section{Results}

\section{Metabolic characterisation of $W T$ and $\mathrm{HL}^{-/-}$mice on a high-fat, high-cholesterol diet}

Two-month-old $W T$ and $H L^{-/-}$male mice were fed with a HFHC diet for 16 weeks and were characterised. HL-deficiency increased total cholesterol $(P<0.0001)$, HDL-cholesterol $(P<0.02)$, triglycerides $(P<0.01)$ and NEFA $(P<0.02)$ (Fig. 1A). No changes were observed in BW between mouse groups (Fig. 1B). Fasting glucose levels were not different between genotypes but $\mathrm{HL}^{-/-}$mice exhibited augmented glucose levels in fed state compared with $W T$ mice (Fig. 1C, $P<0.02)$. Insulin levels were undistinguishable between mice in both fed and overnight-fasted states (Fig. 1D).

Carbohydrate metabolism by GTT showed glucose intolerance in $\mathrm{HL}^{-/-}$mice (Fig. 2A, top panel), as shown by the increased area under the curve (glucose curve vs time, $\mathrm{AUC}_{\text {glucose }}$ right graph $P<0.01$ ), compared with $W T$ mice. Insulin levels during the GTT revealed impaired glucose-stimulated insulin release in $\mathrm{HL}^{-/-}$mice as revealed by decreased $\mathrm{AUC}_{\text {insulin }}$ (insulin curve vs time) value, compared with that in $W T$ mice (Fig. 2A, lower panel $P<0.03)$. No differences between genotypes were found in the ITT, in the corresponding $\mathrm{AUC}_{\text {glucose }}$ (Fig. 2B) or in the HOMA-IR index (Fig. 2C) indicating no difference in insulin sensitivity. Analysis of the in vitro glucose-stimulated insulin secretion in isolated islets from HFHC diet-fed mice, showed reduced secretion in $\mathrm{HL}^{-/-}$mice compared with that of $W T$ mice (Fig. 2D, $P<0.006)$. Thus, HL-deficiency in mice fed a HFHC diet produces glucose intolerance and impaired glucosestimulated insulin-secretion.

Published by Bioscientifica Ltd. 
A
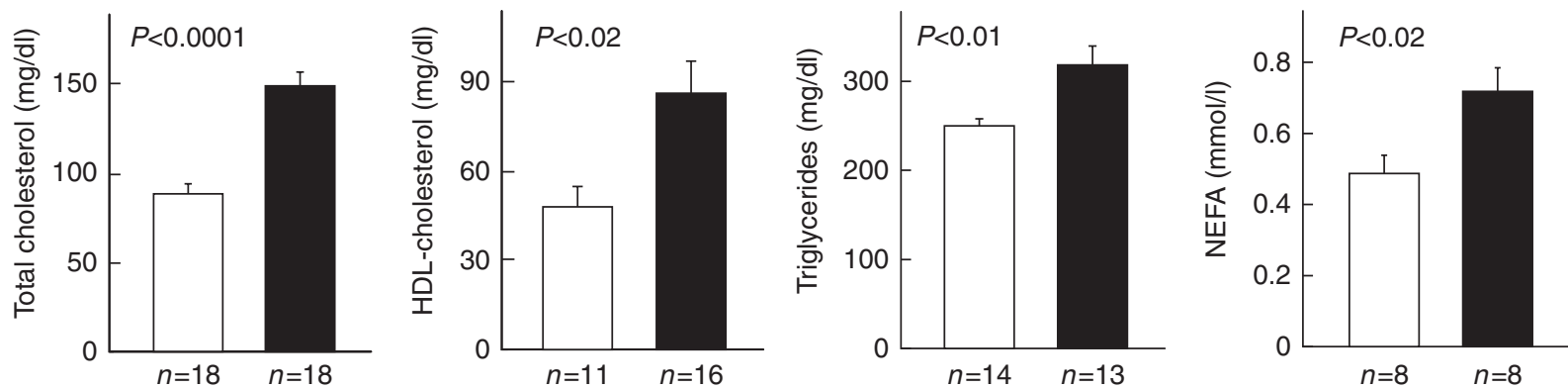

B

C FASTED
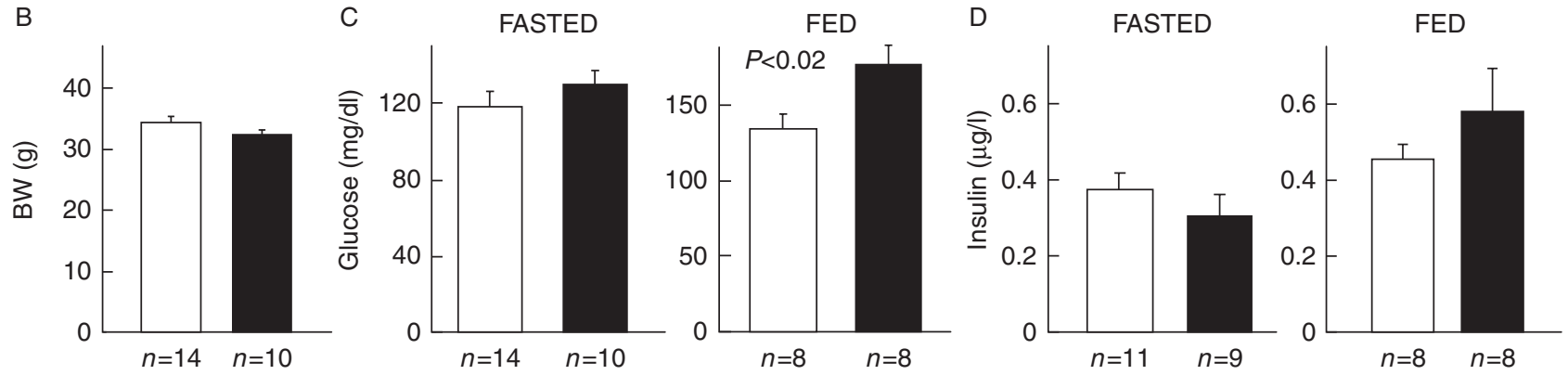

Figure 1

Plasmatic parameters in $W T$ and $H L^{-1-}$ mice placed 4 months on a high-fat, high-cholesterol diet. (A) Total cholesterol, HDL-cholesterol, triglycerides and non-esterified fatty acids in mice. (B) Body weight, (BW) in both groups of mice. (C) Plasma glucose levels in mice fasted overnight (left panel) and in fed state (right panel). (D) Plasma insulin levels in mice fasted overnight (left panel) and in fed state (right panel). Statistical analysis was performed using Student's t-test.

\section{$\mathrm{HL}^{-/-}$mice fed a high-fat, high-cholesterol diet have increased hepatic triglyceride content}

Bearing in mind the complex relationship between NAFLD, dyslipidemia and glucose metabolism derangement, hepatic analysis was next performed. Compared with $W T$ mice, $H L^{-/-}$mice had augmented liver triglyceride content (Fig. 3A, $P<0.04$ ) indicating increased steatosis as shown by the hematoxylin-eosin stained section analysis of both groups of mice (Fig. 3A images). Immunohistochemical analysis of the F4/80 macrophage marker also showed increased (kuppfer) macrophage infiltration in the liver of $H L^{-/-}$mice compared with that in $W T$ mice (Fig. 3B, $P<0.03$ ). Analysis of proinflammatory cytokine expression in the liver demonstrated enhanced mRNA levels of $M c p 1$ in $H L^{-/-}$mice compared with those in $W T$ mice (Fig. 3C, left panel, $P<0.03$ ). No differences between both groups of mice were observed in Tnf $\alpha$ mRNA expression (Fig. 3C, right panel).

These results indicate that HL-deficiency increases fatty liver disease and hepatic inflammation in mice fed with a HFHC diet.

\section{Increased inflammatory state in $\mathrm{HL}^{-/-}$mice}

Analysis of systemic inflammation showed increased circulating MCP1 cytokine levels in $H L^{-/-}$mice compared with those for $W T$ mice (Fig. 4A, $P=0.05$ ). No changes were observed in $\mathrm{TNF} \alpha$ circulating plasma levels. Leukocyte population analysis also revealed enhanced levels of CD115 + monocytes in HL-deficient mice compared with those in $W T$ mice (Fig. 4B, $P<0.03$ ). Similar percentages of the proinflammatory Ly6 $\mathrm{C}^{\text {hi }}$ - and the patrolling $\mathrm{Ly}_{6 \mathrm{C}^{\text {low }}}$. monocyte subsets were similar in both $W T$ and $H L^{-/-}$ mice (Fig. 4B, right panel). T-cell lymphocyte analysis showed increased number of total CD3 + (Fig. 4C, $P<0.04$ ) and CD4+T-lymphocyte subset (Fig. 4C, $P<0.04$ ) without changes in the percentage of the CD8+T-cells or in the activated CD69+-T-cells. Analysis of circulating regulatory $(\mathrm{CD} 4+$ Foxp $3+)$ T-cells showed no differences between both groups of mice but Th17 subtype CD4+Tcells were significantly increased in $H L^{-/-}$mice compared with that in $W T$ mice (Fig. 4D, $P<0.008$ ).

Altogether these results indicate that HL-deficiency in mice, increases inflammation and circulating

Published by Bioscientifica Ltd. 

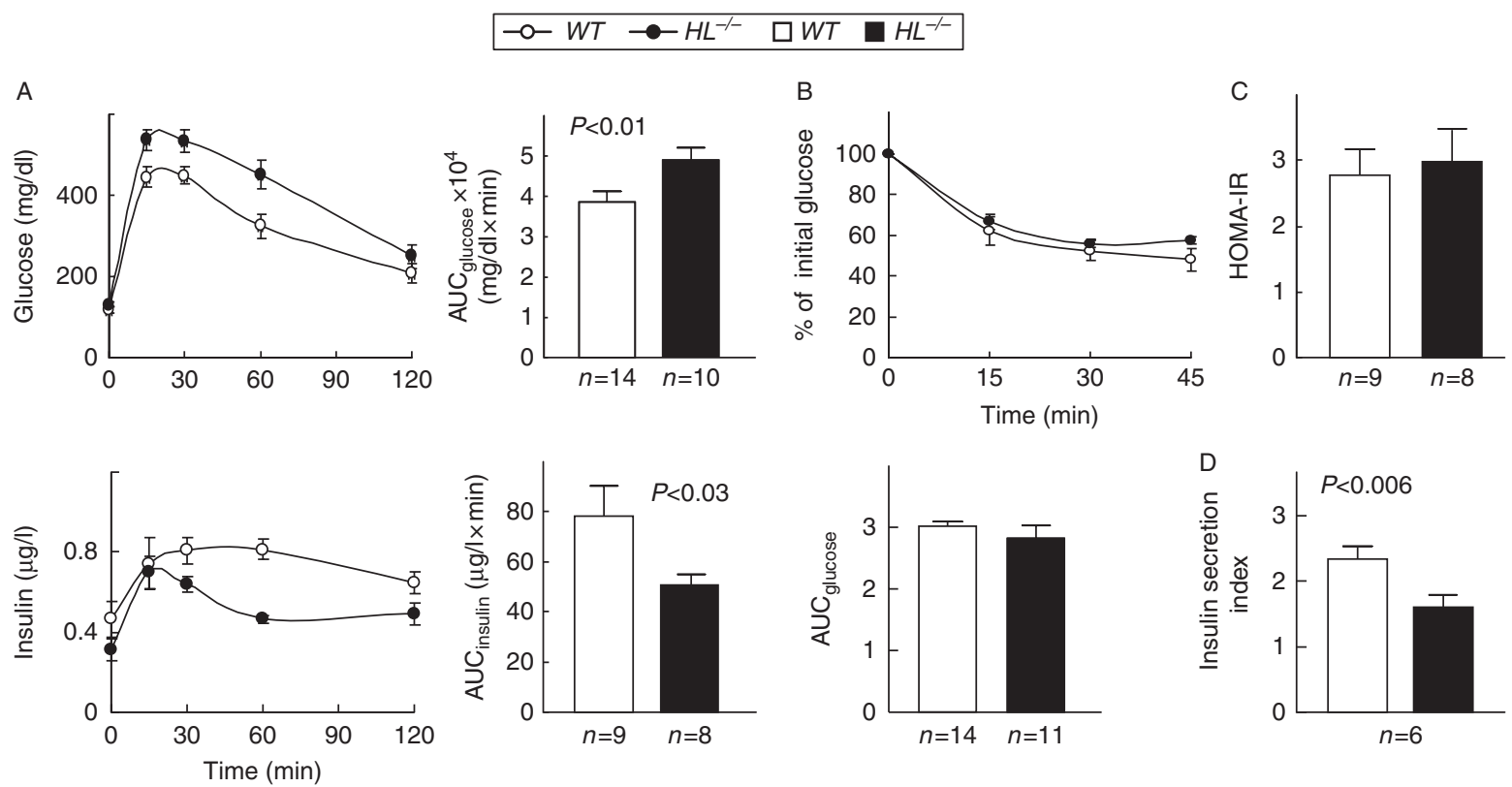

Figure 2

HL deficiency produces glucose intolerance in mice placed on a high-fat, high-cholesterol diet for 4 months. (A) Plasmatic glucose (top panel) and insulin (lower panel) levels at the different time points during the GTT in $W T$ and $H L^{-1-}$ mice which were used to calculate the $A U C_{\text {glucose }}$ and $A U C_{\text {insulin }}$ (right panels). (B) Glucose levels (in percentage relative to the

inflammatory cells including monocytes, CD3+ and CD4+T-cells and the Th17 T-subset cells expressing IL17.

\section{Pancreas characterisation in $\mathrm{HL}^{-/-}$and $W T$ mice}

To explore the differences in glucose-stimulated insulinsecretion between $H L^{-/-}$and $W T$ mice, pancreatic characterisation was next performed. Analysis of pancreatic islets by insulin immunohistochemistry demonstrated no differences in the relative area occupied by $\beta$-cells between $\mathrm{HL}^{-1-}$ and $W T$ mice (Fig. 5A). Similarly, no differences were observed in the $\alpha / \beta$-cell area ratio in pancreatic islets of mice (Fig. 5B). $\beta$-cell proliferation analysis measured as double Ki67/insulin-positive cells, showed similar proliferative rates in $\mathrm{HL}^{-/-}$and $W T$ mice (Fig. 5C). Thus, these results indicate that the observed differences in insulin-secretion were not due to differences in $\beta$-cell mass or $\beta$-cell maintenance.

Given the increase in circulating inflammatory cells in $\mathrm{HL}^{-/-}$mice, inflammatory infiltration was investigated in the pancreas. Analysis of $\mathrm{CD} 3+$-cells in pancreatic sections showed enhanced percentage of T-cells in the exocrine pancreas of $H L^{-/-}$mice compared with that in $W T$ mice (Fig. 5D, $P<0.05$ ). Moreover, analysis of initial glucose levels) during the ITT at $0.5 \mathrm{U} / \mathrm{KgBW}$ in $4 \mathrm{~h}$-fasted $W T$ and $\mathrm{HL}^{-1-}$ mice. The lower graph displays the $\mathrm{AUC}_{\text {glucose }}$ parameter for the two groups of mice. (C) HOMA-IR index in both groups of mice. (D) In vitro insulin secretion of islets from $W T$ and $H L^{-1-}$ mice. Statistical analysis was performed using Student's $t$-test.

inflammatory foci (IF) identified as a mass of cells invading the islets, also revealed augmented inflammation in the exocrine pancreas next to islets in $H L^{-/-}$mice compared with that in $W T$ mice (Fig. 5E, $P<0.007$ ). Thus, HLdeficiency in the mice produces pancreatic inflammation.

\section{Activation of stress-related pathways in $\mathrm{HL}^{-/-}$and WT mice}

Given the observed differences in inflammation and previous studies showing increased activation of the stress-MAPKinases associated with fatty liver disease (Sahini \& Borlak 2014) the activation of these pathways was next evaluated. Protein lysate analysis of the p38 stress-pathway revealed increased (phospho)pp38 levels in the liver from $H L^{-/-}$mice compared with those in $W T$ mice (Fig. 6A, $P<0.003$ ). Similarly, analysis of the activated SAPK/JNK (pSAPK/JNK) protein levels were also higher in the liver of $\mathrm{HL}^{-/-}$mice compared with those in $W T$ mice (Fig. 6B, $P<0.01$ ). No differences in the $p 38$ and Sapk/Ink mRNA levels were observed between genotypes (Fig. 6C). These results indicate increased activation of the stress kinases in $\mathrm{HL}^{-/-}$mice which is consistent with increased inflammatory state.

Published by Bioscientifica Ltd. 
A

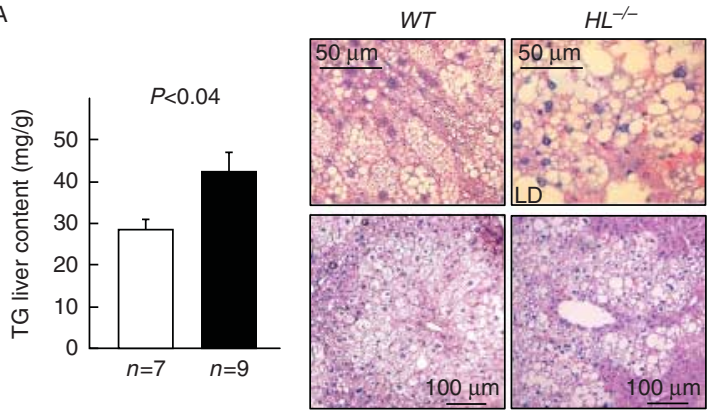

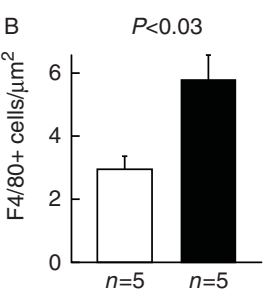
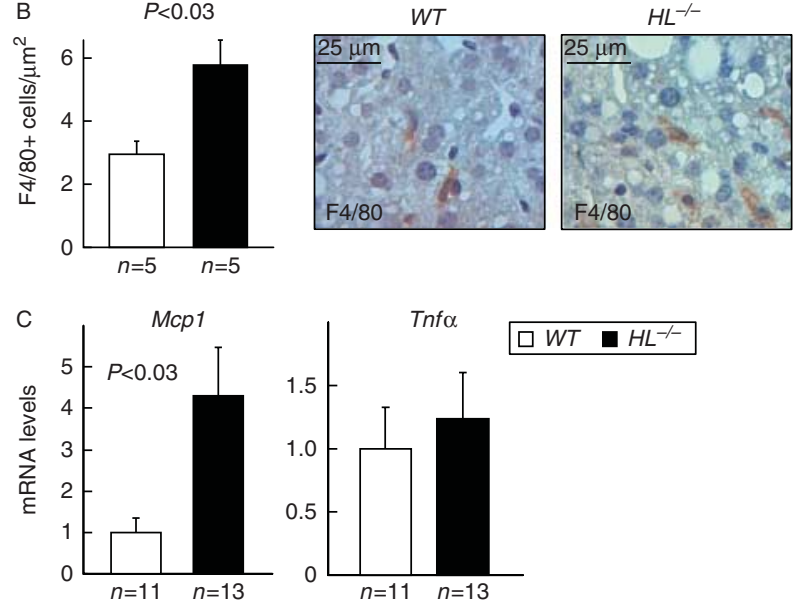

Figure 3

Liver characterisation in $W T$ and $\mathrm{HL}^{-1-}$ mice. (A) Analysis of triglyceride content in liver from both groups of mice. Images of hematoxylin-eosin stained sections showing lipid droplets (LD). (B) Macrophage content ( $\mathrm{F} 4 / 80+$ cells relative to hepatic area) in hepatic cross-sections of mice.

\section{HL-deficiency is not sufficient to induce hepatic steatosis in mice fed regular chow diet}

Dietary cholesterol is an important risk factor for the progression of NAFLD (Wouters, et al. 2008), therefore

Representative images are shown. (C) Quantification of the Mcp1 and Tnf $\alpha$ hepatic mRNA levels normalised to Cyclophilin and relativised to $W T$ mouse mRNA. Statistical analysis was performed using Student's $t$-test. A full colour version of this figure is available via http://dx.doi.org/10.1530/JOE-15-0219.

mice fed RCD were also characterised (Fig. S1, see section on supplementary data given at the end of this article). HL-deficiency increased total cholesterol and triglycerides (Fig. S1A, $P<0.05$ and $P<0.01$, respectively) but no
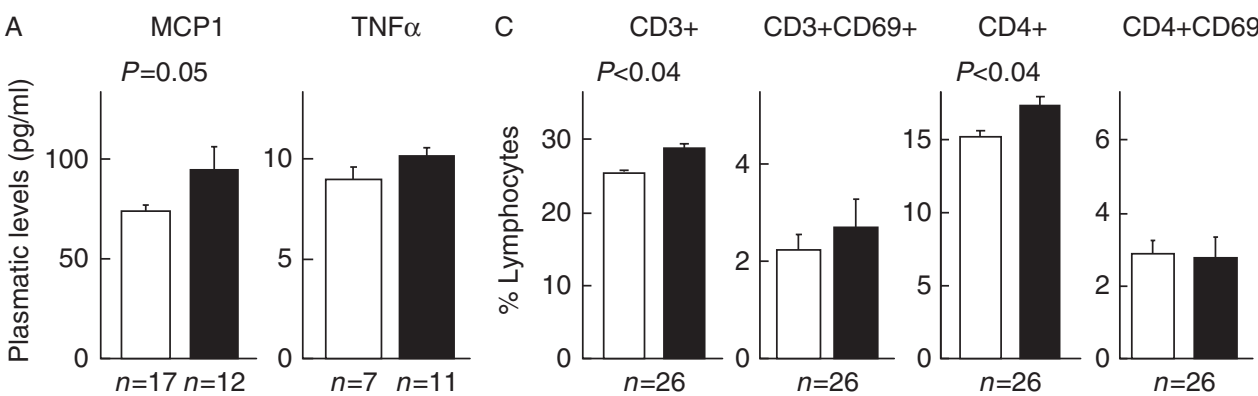

CD8+

CD8+CD69+

B

CD115+

CD115+Ly6C+

$\mathrm{D}$
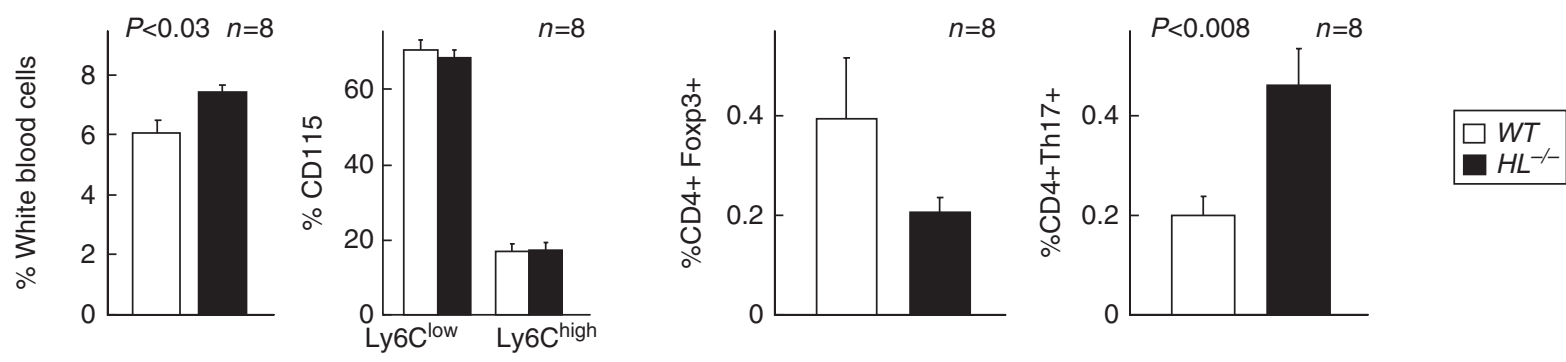

Figure 4

Analysis of inflammation in $W T$ and $H L^{-1-}$ mice. (A) MCP1 and TNF- $\alpha$ circulating plasma levels in mice. (B) Percentage of circulating monocytes identified as CD115+ cells and percentage of Ly6 $\mathrm{C}^{\text {low }}$ and Ly $6 \mathrm{C}^{\text {hi }}$ monocyte subsets in $\mathrm{HL}^{-1-}$ and $W T$ mice analysed by flow cytometry. (C) Percentage of circulating total and activated $(\mathrm{CD} 69+)$ T-lymphocytes $(\mathrm{CD} 3+)$ and
CD4 +, CD8+ and CD8 + CD69+ T-lymphocyte subsets identified by flow cytometry. (D) Percentage of Tregs measured as double CD4+Foxp3+Tcells and CD4 + Th17+-T-cells in both groups of mice. Statistical analysis was performed using Student's $t$-test. http://joe.endocrinology-journals.org DOI: $10.1530 / \mathrm{JOE}-15-0219$
(C) 2015 Society for Endocrinology Printed in Great Britain 
A
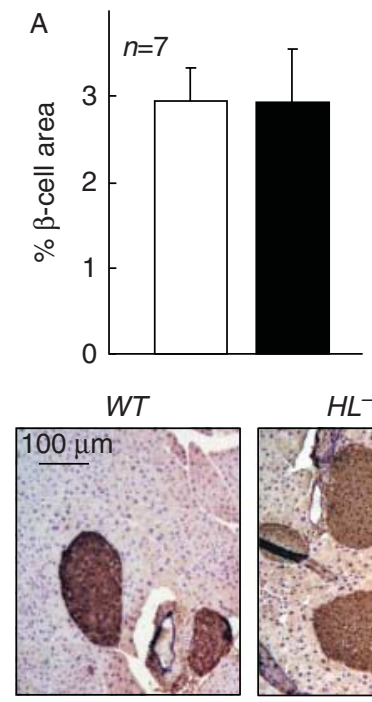

$H L^{-1-}$

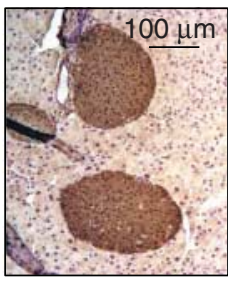

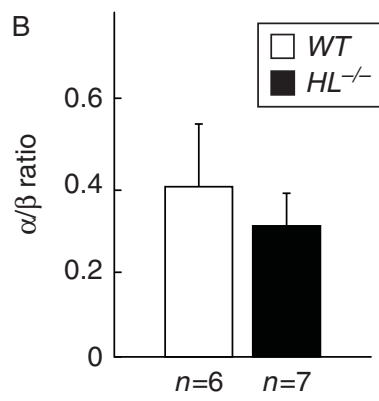

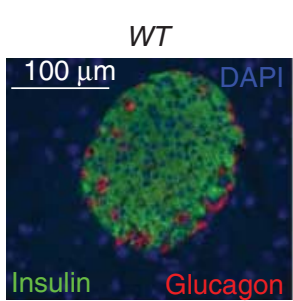

C
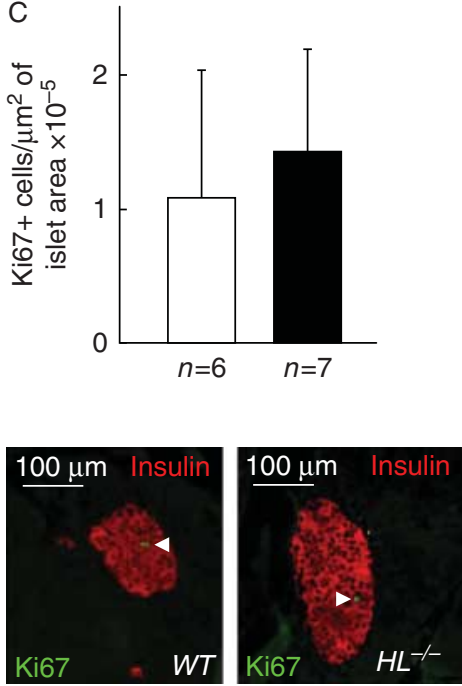

D

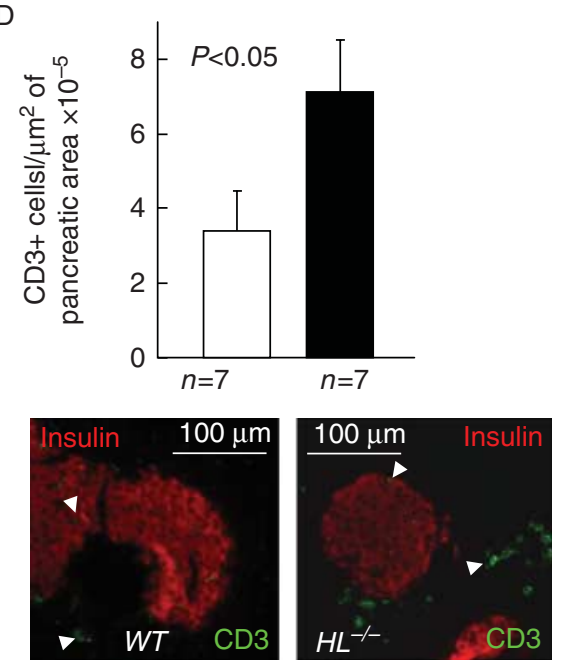

$\mathrm{E}$
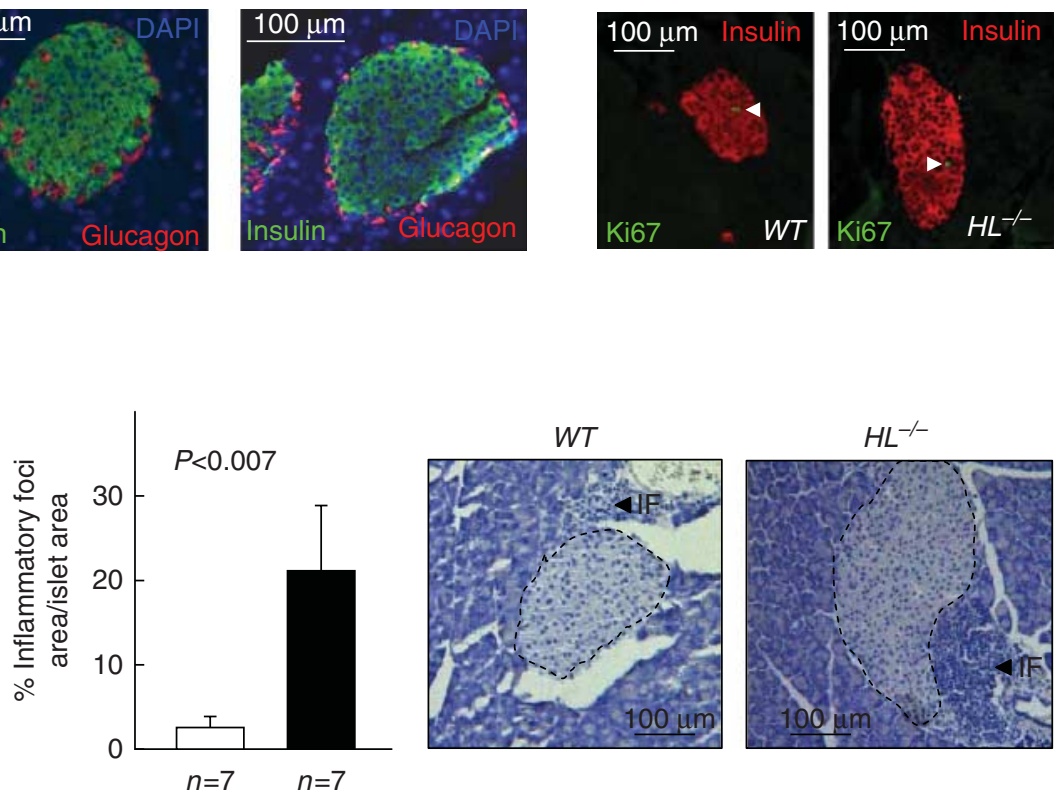

Figure 5

Pancreatic islet characterisation in $W T$ and $H L^{-1-}$ mice. (A) Quantification of $\beta$-cell area (in percentage relative to pancreatic area) identified by antiinsulin immunohistochemistry. (B) Islet $\alpha / \beta$ ratio in the pancreas of both groups of mice. (C) Quantification of proliferating $\beta$-cells, identified as double insulin/Ki67-positive cells relative to islet area determined by inmunofluorescence. (D) T-cell infiltration in the pancreas identified as

differences were observed in BW, glucose or insulin plasmatic levels between genotypes (Figure. S1B). Further analysis showed impaired glucose tolerance, demonstrated by increased $\mathrm{AUC}_{\text {glucose, }}$ (Figure. S1C, right graph $P<0.05)$ in $H L^{-/-}$mice and no changes in glucosestimulated insulin release, as revealed by similar $\mathrm{AUC}_{\text {insulin }}$ (Fig. S1C, lower panel) or in insulin-sensitivity during the ITT, as shown by similar AUC glucose $_{\text {(Fig. S1D). HL- }}$ deficiency in RCD-fed mice produces glucose intolerance but no changes in glucose-stimulated insulin-release.

CD3+-positive cells relative to pancreatic area in both groups of mice. (E) Quantification of area occupied by inflammatory foci (IF) in pancreatic regions next to islets in both groups of mice. Representative images of the immunohistochemistry, immunofluorescence and stainings are shown. Statistical analysis was performed using Student's $t$-test. A full colour version of this figure is available via http://dx.doi.org/10.1530/JOE-15-0219.

Hepatic analysis in $W T$ and $H L^{-/-}$fed RCD revealed no differences in liver triglyceride content and steatosis (Fig. S2A, see section on supplementary data given at the end of this article) as also shown by the hematoxylin-eosin stained sections (images in Fig. S2A). Circulating plasmatic levels of MCP1 and activation of the p38-stress inflammatory pathway (Fig. S2B and C) were indistinguishable between mice indicating similar inflammation in RCD-fed $\mathrm{HL}^{-/-}$and $W T$ mice. Pancreatic analysis revealed increased inflammatory foci, but not significant

Published by Bioscientifica Ltd. 

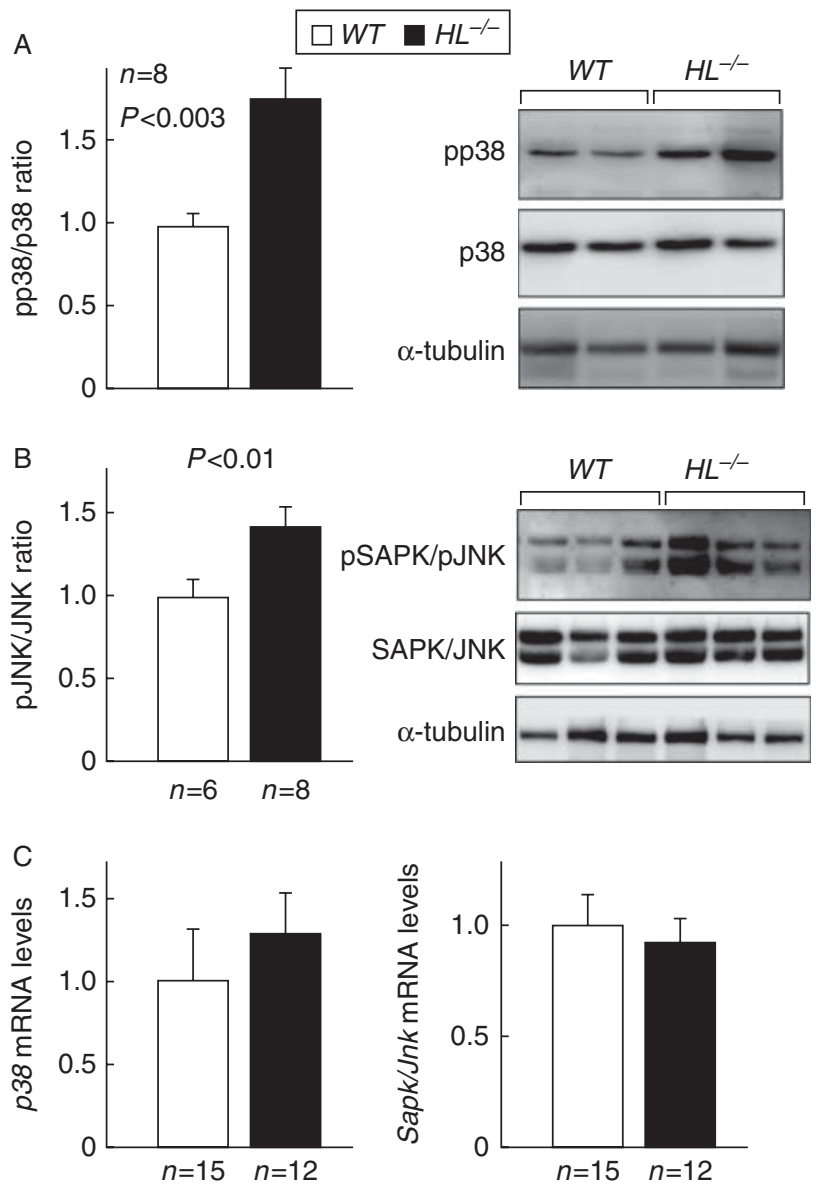

\section{Figure 6}

Stress-kinase expression in liver from $W T$ and $\mathrm{HL}^{-1-}$ mice. (A) Analysis of p38 activated phosphop38 (pp38) and p38 protein levels in livers from both genotypes. (B) Analysis of phospho SAPK/JNK and SAPK/JNK protein levels in liver from both groups of mice. For quantification phosphorylated forms were normalised to total p38 and SAPK/JNK protein levels. Representative blots of the phosphorylated and unphosphorylated proteins of the kinases are shown. Blots showing $\alpha$-tubulin analysis is included as loading controls. (C) Quantification of the p38 (left panel) and Sapk/Jnk (right panel) mRNA expression levels in the mice. The mRNA expression levels were normalised to cyclophilin mRNA levels and relativised to $W T$ mouse mRNA levels. Statistical analysis was performed using Student's $t$-test.

(Fig. S2D) in $\mathrm{HL}^{-/-}$mouse pancreas and no differences in CD3 + content between genotyopes (Fig. S2E). These results indicate that HL-deficiency has no effect on hepatic steatosis or inflammation in mice fed RCD.

\section{Discussion}

MetS and T2DM has become a major health burden to global health, and their incidence is increasing at an alarming rate (Wild et al. 2004). A complex relationship between NAFLD, hypertriglyceridemia, glucose intolerance and MetS exists (Bugianesi et al. 2005). In the present study, we demonstrate that HL-deficiency combined with a HFHC diet in the mice produces hypercholesterolemia, hypertriglyceridemia, increased NEFA levels and glucose intolerance. These metabolic alterations were accompanied by increased hepatic steatosis, hepatic macrophage infiltration and pancreatic inflammation. Moreover, compared with WT mice, systemic inflammation was enhanced in $H L^{-/-}$mice which exhibited monocytosis, higher percentage of the proinflammatory CD4+Th17+-T-cells and augmented levels of MCP1. Analysis of inflammatory stress pathways revealed increased levels of the (activated) pp38- and pSAPK/JNKkinases in $H^{-/-}$mice suggesting a possible role of these signalling-pathways in the metabolic alterations induced by HL-inactivation. Interestingly, $\mathrm{HL}^{-/-}$mice fed RCD diet exhibited glucose intolerance and dyslipidemia, but not systemic inflammation or hepatic steatosis suggesting that the dietary components play a main role in NAFLD and inflammation induced by HL-deficiency. Thus, NAFLD and inflammation seem to be secondary to metabolic alterations (glucose intolerance and dyslipidemia). Altogether, these studies indicate a protective role of HL in fatty liver disease associated with HFHC diet by restoring dyslipidemia, glucose tolerance and by decreasing inflammation.

Previous studies have shown that dyslipidemia, high FFA and hypertriglyceridemia induced by lipasedeficiencies promote hepatic steatosis and NAFLD. Thus, hepatic depletion of adipose triglyceride lipase (ATGL) in mice leads to severe liver steatosis (Ong et al. 2011). Decreased activity of ATGL in the liver of IR patients has also been associated with development of NAFLD (Kato et al. 2008). Consistent with these findings, hepatic overexpression of the hormone-sensitive lipase (HSL) and ATGL promotes fatty acid oxidation, ameliorates steatosis and improves insulin signal transduction in the mice (Reid et al. 2008, Turpin et al. 2011). On the other hand, loss of intracellular TGH/Ces3-lipase which, by contrary, reduces blood lipids and improves glucose tolerance, ameliorated hepatic lipid deposition (Wei et al. 2010). Surprisingly, a previous study reported decreased BW gain and reduced hepatic steatosis in HLdeficient mice (Chiu et al. 2010). These seemingly discrepancy between these later results and the findings of the present study, might be related to the different dietary regimens used in both studies. Chiu and colleagues used an obesogenic diet $(21 \%$ of fat and $0.15 \%$ of cholesterol), which resulted in no differences in cholesterol or in FFA levels while in the present study, the diet contained a $10.8 \%$ fat and $0.75 \%$ of cholesterol which

Published by Bioscientifica Ltd. 
produced higher levels of triglycerides, NEFA and cholesterol. In fact, in the present study when mice were fed RCD $H L^{-/-}$mice did not develop hepatic steatosis or inflammation. Thus, HL-deficiency in combination with a HFHC diet that causes dyslipidemia (hypertriglyceridemia, increased NEFA and high cholesterol) results in hepatic steatosis. Altogether, these studies suggest that elevated NEFA generated from the high triglyceride levels induced by lipase-deficiencies and the presence of dietary cholesterol are key factors for developing hepatic steatosis.

Of note, $H L^{-/-}$mice developed hypercholesterolemia, consisting mostly of high HDL-cholesterol levels, which would rather appear as a protective mechanism of disease progression. In fact, therapies targeted to raise HDL-cholesterol are effective in treating dyslipidemia and disease progression (Rayner et al. 2010, Waksman et al. 2010). Nevertheless, consistent with our findings, recent studies have shown that chronic increased HDL-cholesterol levels produced by some of these therapies, such as long-term therapeutic silencing of miR-33 in mice challenged with a high-fat diet, produced moderate hypertriglyceridemia and hepatic steatosis (Goedeke et al. 2014). Altogether, these data suggest that modulation of lipases that develops with 'toxic' dyslipidemia (hypercholesterolemia, hypertriglyceridemia and high FFA) promote hepatic steatosis and NAFLD.

NAFLD is frequently associated with hepatic IR and MetS (Sabio et al. 2008, Yang et al. 2009, Gruben et al. 2014). Thus, while IR development increases triglyceride accumulation in the liver (Samuel et al. 2010, Samuel \& Shulman 2012), fatty liver produces an excess of glucose and triglycerides, which are key components in IR and MetS (Anstee et al. 2013, Yki-Jarvinen 2014). Consistently, other studies have shown that decreased hepatic steatosis, induced by lipase (ATGL) overproduction is accompanied by improved insulin sensitivity and insulin-signalling (Turpin et al. 2011). In the study presented here, hepatic steatosis in $\mathrm{HL}^{-/-}$mice was accompanied by higher glucose levels in fed state and glucose intolerance. However, HOMA-IR index and sensitivity to insulin in $H L^{-1-}$ mice were similar to those in $W T$ mice indicating no altered insulin sensitivity. Thus, the delayed glucose clearance observed in $H L^{-/-}$mice could be caused by defective insulin secretion by the $\beta$-cells. In fact, insulin secretion during the GTT and in isolated islets revealed an impaired capacity of glucose-stimulated insulin release in $H L-$ deficient mice. Analysis of the pancreases in HFHCdiet fed mice did not revealed differences in $\beta$-cell mass but $H L^{-/-}$mice exhibited inflamed pancreas (with increased T-cells and inflammatory foci) which could mean pancreatic damage affecting pancreas functionality. In support of this hypothesis, high concentrations of FFA, which are present in the plasma of the lipoprotein lipase (LPL)-deficient mice and in patients with hypertriglyceridemia, lead to pancreatic acinar cell damage and are risk factors for acute pancreatitis (Yang et al. 2009). Interestingly, a case-report study showed association between decreased activities of LPL and HL, hypertriglyceridemia and acute pancreatitis (Fujita et al. 2010). Altogether, these studies suggest that hypertriglyceridemia and increased FFA might affect glucose homeostasis by modulating insulin sensitivity but lipase-deficiencies also might impair pancreatic function by promoting tissue inflammation.

Low grade inflammation is also a characteristic of advanced hepatic steatosis or nonalcoholic steatohepatitis (NASH) (Sabio et al. 2008, Yang et al. 2009, Gruben et al. 2014). Fatty liver in $H L^{-/-}$mice was accompanied by augmented hepatic inflammation (macrophage content and Mcp1 mRNA levels) and by increased systemic inflammation including higher circulating MCP1 levels, monocytosis and higher percentage of T-cells. In addition, CD4 + Th17 T-cells, which have been associated to chronic inflammation (Ramesh et al. 2014), were also significantly augmented in $H L^{-/-}$mice compared with those in WT mice. Therefore, HL-deficiency in the mice fed a HFHC diet, which provides dietary cholesterol, produced advanced NAFLD or NASH. $H L^{-/-}$and $W T$ mice fed RCD did not develop systemic inflammation or hepatic steatosis indicating a role of the HFHC diet in the development of fatty liver. Consistent with our findings, dietary cholesterol has been shown to be sufficient to cause hepatic inflammation in steatosis in hyperlipidemic mouse models (Wouters et al. 2008). Altogether, these results indicate that the dyslipidemia in fatty liver disease that develops with high cholesterol levels also enhances the risk of developing inflammatory steatosis or NASH.

Several characteristics of the NAFLD progression, such as hepatocyte ballooning, lead to activation of the stressMAPKinase signalling and previous studies have linked activation of the inflammatory stress-MAPKinases with progression of fatty liver disease (Sahini \& Borlak 2014). In this sense, the activation of JNK as a main mechanism for the development of steatohepatitis has been largely described (Schattenberg et al. 2006, Tuncman et al. 2006, Singh et al. 2009). Others have shown a relevant role of p38-activation in fatty liver disease (Menghini et al. 2012, Nio et al. 2012, Song, et al. 2014). In addition, NEFA liberated by HSL activate both p38 and JNK, and p38 mediates proinflammatory cytokine expression in adipose

Published by Bioscientifica Ltd 
tissue (Mottillo, et al. 2010). On the other hand, lipiddroplet formation in monocytes is mediated by p38 and SAPK/JNK activation (Guijas et al. 2012). In the line of these investigations, when mice were fed a HFHC diet, activation of the p38 and SAPK/JNK-signalling pathways was increased in the liver of $H L^{-/-}$mice compared with that in WT mice. Thus, our investigations suggest that, in HFHC diet, activation of p38 and SAPK/JNK stresspathways seems to mediate progression of hepatic inflammation, and steatosis associated with the glucose metabolism impairment and dyslipidemia (hypercholesterolemia, hypertriglyceridemia and increased NEFA) induced by HL-deficiency.

In summary, the present study demonstrates that the dyslipidemia consisting of hypercholesterolemia, hypertrigliceridemia and increased NEFA induced by HLdeficiency in combination with a HFHC diet, produces hepatic steatosis, hepatic and pancreatic inflammation and glucose intolerance and suggest a protective role of $\mathrm{HL}$ in the development these metabolic alterations. These changes were accompanied by an increase in systemic inflammation with enhanced percentage of monocytes and CD4+Th17-T-cells and MCP1 circulating levels. These events seem to be mediated, at least in part, by the activation of the stress p38- and JNK-signalling kinases in the liver suggesting that modulation of these kinases might prevent fatty liver disease-induced by dyslipidemia and HFHC diet. Future studies are warranted to assess the viability of therapeutic strategies based on the modulation of these kinases to reduce hepatic steatosis/NAFLD, tissue (hepatic and pancreatic) inflammation and glucose intolerance associated to lipase dysfunction.

\section{Supplementary data}

This is linked to the online version of the paper at http://dx.doi.org/10.1530/ JOE-15-0219.

\section{Declaration of interest}

The authors declare that there is no conflict of interest that could be perceived as prejudicing the impartiality of the research reported.

\section{Funding}

This study was supported by grants from the Carlos III Health Institute (FIS: $\mathrm{PI}-\mathrm{CP} 10 / 00555$ and PI13/00834 to HG-N) from the Spanish Ministry of Economy and Competitiveness (SAF2011-23777 to M J S) and from the European Regional Development Fund (FEDER) and research grants from Generalitat Valenciana (GVACOMP2014-006 and PROMETEO II/2013/014). H G-N is an investigator from the 'Miguel Servet' program (CP10/00555). I A-B and A V received salary support from Proyecto Paula. This work was supported by the CIBERDEM, a Carlos III Health Institute initiative.

\section{Author Contribution statement}

I A-B and A H-C participated in the study design, the acquisition and interpretation of data, and in writing the manuscript. A $\mathrm{V}$ performed metabolic studies and characterisation of pancreatic islets. S M-H participated in the design and revised the manuscript. L P and $M J S$ participated in the stress-signalling experiments and inflammatory analysis. D J B participated in the study design and revised the manuscript. H G-N conceived and designed the study, supervised the acquisition of data, interpreted the results and wrote the manuscript.

\section{Acknowledgements}

We thank Dr A Díaz for animal care and G Herrera for flow cytometry.

\section{References}

Anstee QM, Targher G \& Day CP 2013 Progression of NAFLD to diabetes mellitus, cardiovascular disease or cirrhosis. Nature Reviews. Gastroenterology \& Hepatology 10 330-344. (doi:10.1038/nrgastro.2013.41)

Bergeron J, Couillard C, Despres JP, Gagnon J, Leon AS, Rao DC, Skinner JS, Wilmore JH \& Bouchard C 2001 Race differences in the response of postheparin plasma lipoprotein lipase and hepatic lipase activities to endurance exercise training in men: results from the HERITAGE Family Study. Atherosclerosis 159 399-406. (doi:10.1016/S00219150(01)00515-9)

Brunzell JD, Zambon A \& Deeb SS 2011 The effect of hepatic lipase on coronary artery disease in humans is influenced by the underlying lipoprotein phenotype. Biochimica et Biophysica Acta 1821 365-372. (doi:10.1016/j.bbalip.2011.09.008)

Bugianesi E, McCullough AJ \& Marchesini G 2005 Insulin resistance: a metabolic pathway to chronic liver disease. Hepatology 42 987-1000. (doi:10.1002/hep.20920)

Chiu HK, Qian K, Ogimoto K, Morton GJ, Wisse BE, Agrawal N, McDonald TO, Schwartz MW \& Dichek HL 2010 Mice lacking hepatic lipase are lean and protected against diet-induced obesity and hepatic steatosis. Endocrinology 151 993-1001. (doi:10.1210/en.2009-1100)

Dugi KA, Brandauer K, Schmidt N, Nau B, Schneider JG, Mentz S, Keiper T, Schaefer JR, Meissner C, Kather H et al. 2001 Low hepatic lipase activity is a novel risk factor for coronary artery disease. Circulation $\mathbf{1 0 4}$ 3057-3062. (doi:10.1161/hc5001.100795)

Escola-Gil JC, Chen X, Julve J, Quesada H, Santos D, Metso J, Tous M, Jauhiainen M \& Blanco-Vaca F 2013 Hepatic lipase- and endothelial lipase-deficiency in mice promotes macrophage-to-feces RCT and HDL antioxidant properties. Biochimica et Biophysica Acta 1831 691-697. (doi:10.1016/j.bbalip.2013.01.003)

Freeman L, Amar MJ, Shamburek R, Paigen B, Brewer HB Jr, Santamarina-Fojo S \& Gonzalez-Navarro H 2007 Lipolytic and ligand-binding functions of hepatic lipase protect against atherosclerosis in LDL receptor-deficient mice. Journal of Lipid Research 48 104-113. (doi:10.1194/jlr.M600321-JLR200)

Fujita K, Maeda N, Kozawa J, Murano K, Okita K, Iwahashi H, Kihara S, Ishigami M, Omura M, Nakamura T et al. 2010 A case of adolescent hyperlipoproteinemia with xanthoma and acute pancreatitis, associated with decreased activities of lipoprotein lipase and hepatic triglyceride lipase. Internal Medicine 49 2467-2472. (doi:10.2169/ internalmedicine.49.4058)

Goedeke L, Salerno A, Ramirez CM, Guo L, Allen RM, Yin X, Langley SR, Esau C, Wanschel A, Fisher EA et al. 2014 Long-term therapeutic silencing of miR-33 increases circulating triglyceride levels and hepatic lipid accumulation in mice. EMBO Molecular Medicine 6 1133-1141. (doi:10.15252/emmm.201404046)

Gonzalez-Navarro H, Vila-Caballer M, Pastor MF, Vinue A, White MF, Burks D \& Andres V 2007 Plasma insulin levels predict the development

Published by Bioscientifica Ltd 
of atherosclerosis when IRS2 deficiency is combined with severe hypercholesterolemia in apolipoprotein E-null mice. Frontiers in Bioscience 12 2291-2298. (doi:10.2741/2231)

Gonzalez-Navarro H, Vinue A, Vila-Caballer M, Fortuno A, Beloqui O, Zalba G, Burks D, Diez J \& Andres V 2008 Molecular mechanisms of atherosclerosis in metabolic syndrome: role of reduced IRS2-dependent signaling. Arteriosclerosis, Thrombosis, and Vascular Biology 28 2187-2194. (doi:10.1161/ATVBAHA.108.175299)

Gonzalez-Navarro H, Abu Nabah YN, Vinue A, Andres-Manzano MJ, Collado M, Serrano M \& Andres V 2010 p19(ARF) deficiency reduces macrophage and vascular smooth muscle cell apoptosis and aggravates atherosclerosis. Journal of the American College of Cardiology $\mathbf{5 5}$ 2258-2268. (doi:10.1016/j.jacc.2010.01.026)

Gonzalez-Navarro H, Vinue A, Sanz MJ, Delgado M, Pozo MA, Serrano M, Burks DJ \& Andres V 2013 Increased dosage of Ink4/Arf protects against glucose intolerance and insulin resistance associated with aging. Aging Cell 12 102-111. (doi:10.1111/acel.12023)

Gruben N, Shiri-Sverdlov R, Koonen DP \& Hofker MH 2014 Nonalcoholic fatty liver disease: a main driver of insulin resistance or a dangerous liaison? Biochimica et Biophysica Acta 1842 2329-2343. (doi:10.1016/ j.bbadis.2014.08.004)

Guijas C, Perez-Chacon G, Astudillo AM, Rubio JM, Gil-de-Gomez L, Balboa MA \& Balsinde J 2012 Simultaneous activation of p38 and JNK by arachidonic acid stimulates the cytosolic phospholipase A2-dependent synthesis of lipid droplets in human monocytes. Journal of Lipid Research 53 2343-2354. (doi:10.1194/jlr.M028423)

Homanics GE, de Silva HV, Osada J, Zhang SH, Wong H, Borensztajn J \& Maeda N 1995 Mild dyslipidemia in mice following targeted inactivation of the hepatic lipase gene. Journal of Biological Chemistry $\mathbf{2 7 0}$ 2974-2980. (doi:10.1074/jbc.270.7.2974)

Kato M, Higuchi N \& Enjoji M 2008 Reduced hepatic expression of adipose tissue triglyceride lipase and CGI-58 may contribute to the development of non-alcoholic fatty liver disease in patients with insulin resistance. Scandinavian Journal of Gastroenterology 43 1018-1019. (doi:10.1080/00365520802008140)

Marchesini G \& Marzocchi R 2007 Metabolic syndrome and NASH. Clinics in Liver Disease 11 105-117, ix. (doi:10.1016/j.cld.2007.02.013)

Martinez-Hervas S, Vinue A, Nunez L, Andres-Blasco I, Piqueras L, Real JT, Ascaso JF, Burks DJ, Sanz MJ \& Gonzalez-Navarro H 2014 Insulin resistance aggravates atherosclerosis by reducing vascular smooth muscle cell survival and increasing CX3CL1/CX3CR1 axis. Cardiovascular Research 103 324-336. (doi:10.1093/cvr/cvu115)

Menghini R, Casagrande V, Menini S, Marino A, Marzano V, Hribal ML, Gentileschi P, Lauro D, Schillaci O, Pugliese G et al. 2012 TIMP3 overexpression in macrophages protects from insulin resistance, adipose inflammation, and nonalcoholic fatty liver disease in mice. Diabetes 61 454-462. (doi:10.2337/db11-0613)

Mezdour H, Jones R, Dengremont C, Castro G \& Maeda N 1997 Hepatic lipase deficiency increases plasma cholesterol but reduces susceptibility to atherosclerosis in apolipoprotein E-deficient mice. Journal of Biological Chemistry 272 13570-13575. (doi:10.1074/jbc.272.21.13570)

Mitsutake S, Zama K, Yokota H, Yoshida T, Tanaka M, Mitsui M, Ikawa M, Okabe M, Tanaka Y, Yamashita T et al. 2011 Dynamic modification of sphingomyelin in lipid microdomains controls development of obesity, fatty liver, and type 2 diabetes. Journal of Biological Chemistry 286 28544-28555. (doi:10.1074/jbc.M111.255646)

Mottillo EP, Shen XJ \& Granneman JG 2010 ß3-adrenergic receptor induction of adipocyte inflammation requires lipolytic activation of stress kinases p38 and JNK. Biochimica et Biophysica Acta 1801 1048-1055. (doi:10.1016/j.bbalip.2010.04.012)

Nio Y, Yamauchi T, Iwabu M, Okada-Iwabu M, Funata M, Yamaguchi M, Ueki K \& Kadowaki T 2012 Monocyte chemoattractant protein-1 (MCP-1) deficiency enhances alternatively activated M2 macrophages and ameliorates insulin resistance and fatty liver in lipoatrophic diabetic A-ZIP transgenic mice. Diabetologia 55 3350-3358. (doi:10.1007/s00125-012-2710-2)
Norris AW, Chen L, Fisher SJ, Szanto I, Ristow M, Jozsi AC, Hirshman MF, Rosen ED, Goodyear LJ, Gonzalez FJ et al. 2003 Muscle-specific PPAR $\gamma$ deficient mice develop increased adiposity and insulin resistance but respond to thiazolidinediones. Journal of Clinical Investigation 112 608-618. (doi:10.1172/JCI17305)

Ong KT, Mashek MT, Bu SY, Greenberg AS \& Mashek DG 2011 Adipose triglyceride lipase is a major hepatic lipase that regulates triacylglycerol turnover and fatty acid signaling and partitioning. Hepatology $\mathbf{5 3}$ 116-126. (doi:10.1002/hep.24006)

Ramesh R, Kozhaya L, McKevitt K, Djuretic IM, Carlson TJ, Quintero MA, McCauley JL, Abreu MT, Unutmaz D \& Sundrud MS 2014 Proinflammatory human Th17 cells selectively express P-glycoprotein and are refractory to glucocorticoids. Journal of Experimental Medicine $\mathbf{2 1 1}$ 89-104. (doi:10.1084/jem.20130301)

Rayner KJ, Suarez Y, Davalos A, Parathath S, Fitzgerald ML, Tamehiro N, Fisher EA, Moore KJ \& Fernandez-Hernando C 2010 MiR-33 contributes to the regulation of cholesterol homeostasis. Science 328 1570-1573. (doi:10.1126/science.1189862)

Reid BN, Ables GP, Otlivanchik OA, Schoiswohl G, Zechner R, Blaner WS, Goldberg IJ, Schwabe RF, Chua SC Jr \& Huang LS 2008 Hepatic overexpression of hormone-sensitive lipase and adipose triglyceride lipase promotes fatty acid oxidation, stimulates direct release of free fatty acids, and ameliorates steatosis. Journal of Biological Chemistry $\mathbf{2 8 3}$ 13087-13099. (doi:10.1074/jbc.M800533200)

Sabio G, Das M, Mora A, Zhang Z, Jun JY, Ko HJ, Barrett T, Kim JK \& Davis RJ 2008 A stress signaling pathway in adipose tissue regulates hepatic insulin resistance. Science 322 1539-1543. (doi:10.1126/science. 1160794)

Sahini N \& Borlak J 2014 Recent insights into the molecular pathophysiology of lipid droplet formation in hepatocytes. Progress in Lipid Research 54 86-112. (doi:10.1016/j.plipres.2014.02.002)

Samuel VT \& Shulman GI 2012 Mechanisms for insulin resistance: common threads and missing links. Cell 148 852-871. (doi:10.1016/j.cell.2012.02.017)

Samuel VT, Petersen KF \& Shulman GI 2010 Lipid-induced insulin resistance: unravelling the mechanism. Lancet 375 2267-2277. (doi:10.1016/S0140-6736(10)60408-4)

Santamarina-Fojo S, Gonzalez-Navarro H, Freeman L, Wagner E \& Nong Z 2004 Hepatic lipase, lipoprotein metabolism, and atherogenesis. Arteriosclerosis, Thrombosis, and Vascular Biology 24 1750-1754. (doi:10.1161/01.ATV.0000140818.00570.2d)

Schattenberg JM, Singh R, Wang Y, Lefkowitch JH, Rigoli RM, Scherer PE \& Czaja MJ 2006 JNK1 but not JNK2 promotes the development of steatohepatitis in mice. Hepatology 43 163-172. (doi:10.1002/hep. 20999)

Singh R, Wang Y, Xiang Y, Tanaka KE, Gaarde WA \& Czaja MJ 2009 Differential effects of JNK1 and JNK2 inhibition on murine steatohepatitis and insulin resistance. Hepatology 49 87-96. (doi:10.1002/hep. 22578)

Song Y, Li X, Li Y, Li N, Shi X, Ding H, Zhang Y, Li X, Liu G \& Wang Z 2014 Non-esterified fatty acids activate the ROS-p38-p53/Nrf2 signaling pathway to induce bovine hepatocyte apoptosis in vitro. Apoptosis 19 984-997. (doi:10.1007/s10495-014-0982-3)

Teran-Garcia M, Santoro N, Rankinen T, Bergeron J, Rice T, Leon AS, Rao DC, Skinner JS, Bergman RN, Despres JP et al. 2005 Hepatic lipase gene variant $-514 \mathrm{C}>\mathrm{T}$ is associated with lipoprotein and insulin sensitivity response to regular exercise: the HERITAGE Family Study. Diabetes 54 2251-2255. (doi:10.2337/diabetes.54.7.2251)

Teslovich TM, Musunuru K, Smith AV, Edmondson AC, Stylianou IM, Koseki M, Pirruccello JP, Ripatti S, Chasman DI, Willer CJ et al. 2010 Biological, clinical and population relevance of 95 loci for blood lipids. Nature 466 707-713. (doi:10.1038/nature09270)

Todorova B, Kubaszek A, Pihlajamaki J, Lindstrom J, Eriksson J, Valle TT, Hamalainen H, Ilanne-Parikka P, Keinanen-Kiukaanniemi S, Tuomilehto J et al. 2004 The G-250A promoter polymorphism of the hepatic lipase gene predicts the conversion from impaired glucose tolerance to 
type 2 diabetes mellitus: the Finnish Diabetes Prevention Study. Journal of Clinical Endocrinology and Metabolism 89 2019-2023. (doi:10.1210/jc.2003-031325)

Tuncman G, Hirosumi J, Solinas G, Chang L, Karin M \& Hotamisligil GS 2006 Functional in vivo interactions between JNK1 and JNK2 isoforms in obesity and insulin resistance. PNAS 103 10741-10746. (doi:10.1073/pnas.0603509103)

Turpin SM, Hoy AJ, Brown RD, Rudaz CG, Honeyman J, Matzaris M \& Watt MJ 2011 Adipose triacylglycerol lipase is a major regulator of hepatic lipid metabolism but not insulin sensitivity in mice. Diabetologia 54 146-156. (doi:10.1007/s00125-010-1895-5)

Vinue A, Andres-Blasco I, Herrero-Cervera A, Piqueras L, Andres V, Burks DJ, Sanz MJ \& Gonzalez-Navarro H 2015 Ink4/Arf locus restores glucose tolerance and insulin sensitivity by reducing hepatic steatosis and inflammation in mice with impaired IRS2-dependent signalling. Biochimica et Biophysica Acta 1852 1729-1742. (doi:10.1016/j.bbadis. 2015.05.013)

Waksman R, Torguson R, Kent KM, Pichard AD, Suddath WO, Satler LF, Martin BD, Perlman TJ, Maltais JA, Weissman NJ et al. 2010 A first-inman, randomized, placebo-controlled study to evaluate the safety and feasibility of autologous delipidated high-density lipoprotein plasma infusions in patients with acute coronary syndrome. Journal of the American College of Cardiology 55 2727-2735. (doi:10.1016/j.jacc. 2009.12.067)

Wei E, Ben Ali Y, Lyon J, Wang H, Nelson R, Dolinsky VW, Dyck JR, Mitchell G, Korbutt GS \& Lehner R 2010 Loss of TGH/Ces3 in mice decreases blood lipids, improves glucose tolerance, and increases energy expenditure. Cell Metabolism 11 183-193. (doi:10.1016/j.cmet. 2010.02.005)

Wild S, Roglic G, Green A, Sicree R \& King H 2004 Global prevalence of diabetes: estimates for the year 2000 and projections for 2030. Diabetes Care 27 1047-1053. (doi:10.2337/diacare.27.5.1047)

Wouters K, van Gorp PJ, Bieghs V, Gijbels MJ, Duimel H, Lutjohann D, Kerksiek A, van Kruchten R, Maeda N, Staels B et al. 2008 Dietary cholesterol, rather than liver steatosis, leads to hepatic inflammation in hyperlipidemic mouse models of nonalcoholic steatohepatitis. Hepatology 48 474-486. (doi:10.1002/hep.22363)

Yang F, Wang Y, Sternfeld L, Rodriguez JA, Ross C, Hayden MR, Carriere F, Liu G \& Schulz I 2009 The role of free fatty acids, pancreatic lipase and $\mathrm{Ca}+$ signalling in injury of isolated acinar cells and pancreatitis model in lipoprotein lipase-deficient mice. Acta Physiologica 195 13-28. (doi:10.1111/j.1748-1716.2008.01933.x)

Yki-Jarvinen H 2014 Non-alcoholic fatty liver disease as a cause and a consequence of metabolic syndrome. Lancet 2 901-910. (doi:10.1016/S2213-8587(14)70032-4)

Zambon S, Zanoni S, Romanato G, Corti MC, Noale M, Sartori L, Musacchio E, Baggio G, Crepaldi G \& Manzato E 2009 Metabolic syndrome and allcause and cardiovascular mortality in an Italian elderly population: the Progetto Veneto Anziani (Pro.V.A.) Study. Diabetes Care 32 153-159. (doi:10.2337/dc08-1256)

Zhang C, Lopez-Ridaura R, Rimm EB, Li T, Hunter DJ \& Hu FB 2006 Genetic variation in the hepatic lipase gene and the risk of coronary heart disease among US diabetic men: potential interaction with obesity. Diabetologia 49 1552-1559. (doi:10.1007/s00125-006-0235-2)

Received in final form 3 September 2015

Accepted 30 September 2015

Accepted Preprint published online 30 September 2015
(C) 2015 Society for Endocrinology Printed in Great Britain 